\section{Postreinforcement pause duration on fixed-interval and-fixed time schedules of food reinforcement*}

\author{
RICHARD L. SHULL \\ University of North Carolina at Greensboro, Greensboro, N.C. 27412
}

Three pigeons were studied under three different schedules that arranged equivalent constant minimum-time intervals between food presentations. In the first, a fixed-interval schedule, reinforcement depended on a response after $2 \mathrm{~min}$ had elapsed. In the second, a conjunctive fixed-time fixed-ratio 1 schedule, reinforcement depended on an elapsed 2-min interval and a response without regard to order. In the third, a fixed-time schedule, food was presented every $2 \mathrm{~min}$ without regard to the bird's responding. Response rates were much lower under the latter two schedules than under the fixed-interval schedule. Postreinforcement pauses were about equal under all three conditions, provided the duration of the postreinforcement pause for the fixed-time schedule was based only on intervals containing at least one response.

Fixed-interval (FI) schedules require a response after a fixed-time (FT) interval has elapsed for reinforcement. FI schedules characteristically generate a behavior pattern consisting of a postreinforcement pause of about half the FI duration followed by a moderate rate of responding until the next reinforcement. Both the requirement that a response follow the elapsing of the FI and the constancy of the intervals separating reinforcement contribute to the response rate and pattern (Zeiler, 1968; Shull, 1970). One study (Shull, 1970) compared the performance on a FI schedule with the performance on a schedule that made reinforcement depend on a response and an elapsed time interval without regard to order. That is, food was presented automatically at the end of a FT interval, provided a response had occurred sometime during the interval. With this schedule (a conj FT FR 1 schedule), a considerable delay could intervene between reinforcement and the preceding keypeck. When the in terreinforcement intervals were equal, the conj FT FR 1 schedule and the FI schedule produced about equal postreinforcement pauses. However, the conj FT FR 1 schedule maintained much lower response rates. The response pattern generated by the conj FT FR 1 schedule consisted of a postreinforcement pause of about half the FI, a few responses, then a subsequent pause until reinforcement. That experiment showed that postreinforcement pause remained constant even when the schedule was changed to eliminate the necessity of a

*This research was supported by a grant from the UNC-G Research Council. I thank William Witty and Marilyn Guilkey for help in running the experiment. close temporal contiguity between a response and reinforcement.

The purpose of the present study was to evaluate further the role of requiring a response in controlling responding in FI schedules. The logic of the experiment consisted of comparing postreinforcement pauses and response rates on standard FI schedules, conj FT FR 1 schedules, and FT schedules, arranging the same minimum interreinforcement interval. The FI schedule requires a response after the fixed interval-i.e., order is specified. The conj FT FR 1 schedule also requires a response for reinforcement but relaxes the order requirement of FI schedules. The FT schedule totally eliminates the response requirement. Thus, the three schedules can be viewed as a continuum of constraints imposed on the response requirement. SUBJECTS

Three adult male Silver King pigeons, reduced to approximately $80 \%$ of their free-feeding weights, served as Ss. The birds had previously been on FI schedules under several levels of deprivation.

\section{APPARATUS}

The experimental chamber was enclosed in a sound-attenuating box. White noise and a ventilating fan provided masking noise. On one wall of the chamber was a 0.75 -in.- (2-cm) diam response key that could be transilluminated from behind with a blue light and had an opening for presenting mixed grain. When the key was transilluminated, a force exceeding $20 \mathrm{~g}(0.20 \mathrm{~N})$ to the key broke an electrical contact that operated control and recording circuits and also produced a feedback click. The key was disconnected from the control circuits when darkened. Reinforcement consisted of a 4-sec access to grain. During reinforcement, the key was darkened and the feeder illuminated. Power for the keylight was obtained from a transformer isolated from the main power supply. The feeder light and the keylight were the only sources of illumination in the chamber.

\section{PROCEDURE}

The baseline condition was a standard FI 2-min schedule, i.e., the first response after $2 \mathrm{~min}$ had elapsed since the termination of the preceding reinforcement produced food.

Like the FI 2-min schedule, the conj FT 2-min FR 1 schedule required a response and an elapsed time interval for reinforcement. However, with the conj FT 2-min FR 1 schedule, reinforcement was presented automatically at the end of the 2-min interval, provided a response had been made during the interval. If the interval had elapsed without a response having been made, the first response after the interval elapsed produced reinforcement. Thus, the conj FT 2-min FR 1 schedule permitted a substantial delay to intervene between a reinforcement and the preceding response.

On the FT 2-min schedule, grain was presented at 2-min intervals without regard to the bird's responding.

Sessions were run daily. Each session terminated automatically after the 40th reinforcement. The actual sequence of conditions is indicated below. The number in parentheses indicates the number of sessions devoted to each condition: FI 2-min (50); FT 2-min (40); conj FT 2-min FR 1 (20); FI 2-min (20).

RESULTS AND DISCUSSION

Th e purpase of the experiment was to study the effect of the response requirement on response rate and postreinforcement pause. The top panel of Fig. 1 shows, for each bird, the overall response rates for the three conditions. Overall response rates were determined by dividing the number of responses in a session by the accumulated session time less the time that the feeder was presented. The points in Fig. 1 are means of the last 10 sessions of each condition. For all birds, response rates were very much lower under the conj FT 2-min FR 1 and FT 2-min schedules than under the FI 2-min schedule. For Birds B2 and $B 3$, response rates were higher on the conj FT 2-min FR 1 than on the FT 2-min schedule.

The mean postreinforcement pause is the average amount of time between reinforcement and the first response after reinforcement. Since the FI 2-min schedule and the conj FT 2-min FR 1 schedule required a 


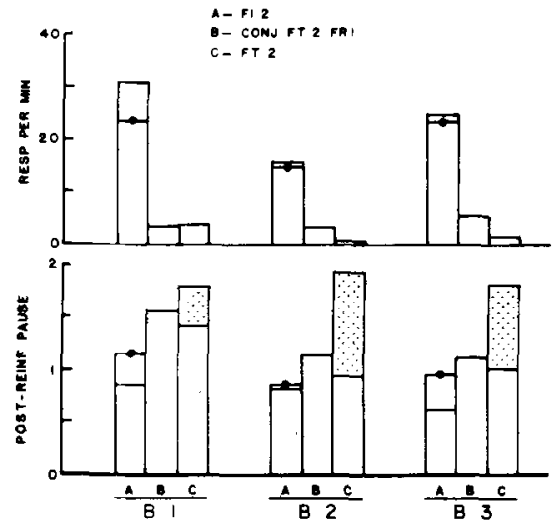

Fig. 1. Mean overall responses per minute (top panel) and mean postreinforcement pause in minutes (bottom panel) for the three experimental conditions. Means are based on the last 10 sessions of a condition. Dots indicate redeterminations. For the FT 2 schedule (Condition C), the height of the open bars indicates the mean postreinforcement pause for intervals in which at least one response occurred; the height of the stippled bars indicates the mean postreinforcement pause for all intervals, with intervals without a response being treated as $2-\mathrm{min}$ postreinforcement pauses.

response in each interval, there was a postreinforcement pause for each interval. However, with the FT 2-min schedule it was possible for there to be no responses in an interval and, therefore, no postreinforcement pause. One solution of this problem is to consider each interval without a response as a 2 -min postreinforcement pause. Another solution is to compute mean postreinforcement pause only on those intervals in which at least one response occurred. Since the birds responded in about $10 \%$ of the intervals during the last 10 sessions of the FT 2-min schedule, this latter computation is based on a relatively smaller sample.

The lower panel of Fig. 1 shows mean postreinforcement pause duration for each of the schedules for each bird. For the FT 2-min schedule, Fig. 1 'shows mean postreinforcement pause durations based on both rationales. For the other two schedules, few postreinforcement pa u s s exceded $2 \mathrm{~min}$. Postreinforcement pauses for $\mathrm{B} 2$ and B3 were about equal under the three schedules when the postreinforcement pause for the FT 2-min schedule is based on intervals in which at least one response was made. For the same comparison, the postreinforcement pauses for $B 1$ were longer on the conj FT 2-min FR 1 and FT 2-min schedules than on the FI 2-min schedule. Considering no-response intervals as 2-min postreinforcement pauses, the FI $2-\mathrm{min}$ schedule produced much longer postreinforcement pauses than the other schedules for all birds.

When the comparison is based on intervals in which at least one response occurred under the FT 2-min schedule, the three schedules generated ap proximately equivalent postreinforcement pauses, despite large differences in response rates. These data support the functional i n d e p e ndence of the postreinforcement pause and response rate reported previously (Farmer \& Schoenfeld, 1964; Neuringer \& Schneider, 1968; Killeen, 1968; Shull, 1970).

For the conj FT 2-min FR 1 and the F T 2-min schedules, the postreinforcement pause and the response rate data were quite similar. Inspection of cumulative records confirmed that these two schedules generated very similar response patterns. The predominant pattern for B2 and B3 on both schedules consisted of a pause of about half of the interval, a brief period of responding, and then a subsequent pause until reinforcement. The FT 2-min schedule differed from the conj FT 2-min FR 1 schedule by having a large proportion of interreinforcement intervals without any responding at all. The response patterns of $\mathrm{B} 1$ on the conj FT 2-min FR 1 and FT 2-min schedules were different from those of $\mathrm{B} 2$ and $\mathrm{B} 3$. He tended to pause longer than half of the interreinforcement interval and then to respond at a moderate rate until reinforcement.

These data suggest that requiring a close temporal association between a peck and reinforcement may determine the rate of pecking but not the duration of the pause after reinforcement (Shull, 1970). The interreinforcement interval-or some factor correlated with the interreinforcement interval, such as the delay between the first response after reinforcement and the next reinforcement-controls the postreinforcement pause duration but not the response rate. Whether or not a response is required at all in each interreinforcement interval seems to determine the proportion of intervals containing responding but not the temporal patterning of those responses.

The generality of these findings may be limited to situations in which the birds have had extensive training on regular FI schedules, as in this study. Neuringer (1970) reinforced the first three pecks made by naive pigeons with food. Thereafter, all food presentations occurred independently of the bird's responding. After extensive training on a FT 2-min schedule, Neuringer's birds tended to respond at a high rate immediately after reinforcement and then pause for the remainder of the interval.

\section{REFERENCES}

FARMER, J., \& SCHOENFELD, $\mathrm{W}, \mathrm{N}$ Effects of a DRL contingency added to a fixed-interval reinforcement schedule. Journal of the Experimental Analy sis of Behavior, 1964, 7, 391-399.

KILLEEN, P. Reinforcement frequency and contingency as factors in fixed-ratio behavior. Journal of the Experimental Analysis of Behavior, 1969, 12, 391-395.

NEURINGER, A. J. Superstitious key pecking after three peck-produced reinforcements. Journal of the Expeximental Analysis of Behavior, 1970, $13,127-134$.

NEURINGER, A. J., \& SCHNEIDER, B. A. Separating the effects of interreinforcement time and number of interreinforcement responses. Journal of the Experimental Analysis of Behavior, $1969,11,661-667$.

SHULL, R. L. The response-reinforcement dependency in fixed-interval schedules of reinforcement. Journal of the Experimental Analysis of Behavior, 1970, 14, 55-60.

ZEILER, M. D. Fixed and variable schedules of response-independent reinforcement. Journal of the Experimental Analysis of Behavior, 1968, 11, 405-414. 